\title{
Relaxing Method in the Evaluation of MPPT of Photovoltaic Cells Based on MIT Modeling
}

\author{
Amir Majid \\ College of Engineering and IT, University of Science and Technology, Fujairah POB 2202, U.A.E.
}

Corresponding Author Email: a.abdulmajid@ustf.ac.ae

https://doi.org/10.18280/mmep.080120

Received: 28 October 2020

Accepted: 4 January 2021

\section{Keywords:}

controlled voltage, irradiance, MIT, MPP, modeling, load resistance, relaxation

\begin{abstract}
A relaxation method is proposed to determine the maximum power point tracking of a small to medium powered photovoltaic module, based on the non referenced MIT model, with analytical evaluation of the maximum power of the generated voltage. In implementing this algorithm, there is no need for continuous online measurements of temperature or irradiance, which are the most used variables used in the evaluation of the I-V relationship of PV cells. The method has the advantage of adequate accuracy without any oscillations, compared with certain conventional methods. The method can track accurately the maximum power point under changes in atmospheric conditions and load variations, by referring it with the MIT model.
\end{abstract}

\section{INTRODUCTION}

Renewable energy systems are now widely installed in many places and countries, being competitive sources of electrical power that are free, environment friendly, and with long lifetime. Solar energy systems and particularly photovoltaic (PV) modules are mostly popular due to the ease of converting sun energy to heat and electricity. PV cells are devices that convert solar energy into electricity in a clean way without pollution, that can be used as an alternative solution of fuel power generation in domestic and industrial applications, especially in remote areas. They can be installed as stand alone, grid connected, or as hybrid with other power generating methods.

Although PV modules and panels are easy to be installed their performances are influenced by many factors, such as orientation, weather conditions and their performance in extracting maximum power from solar rays. An overall optimization of the system should be performed to achieve the best possible performance, with the use of measurement equipment, power converters, load and/or grid connection. Several methods have been proposed and studied in the literature to deal with different aspects and cases of solar extraction and control strategies for solar regulators $[1,2]$.

In contrast to fuel power generating systems, PV modules have rather low power efficiency, and as a result all means are required to maximize this efficiency. One of the most widely implemented technique used to increase efficiency and maximize energy extraction, is the maximum power point tracking (MPPT) method [3, 4], which considers for a certain load, the effect of mainly the solar irradiation and PV cell temperature.

A negative feedback control is employed to track maximum power with the use of output voltage as a reference in a loop to adjust maximum power extracted, using power electronic converters, as depicted in Figure 1, in which the photovoltaic voltage is compared with the maximum power point voltage under standard test conditions (STC), and the error is used to adjust the duty cycle (D) of a regulator or DC/DC converter.

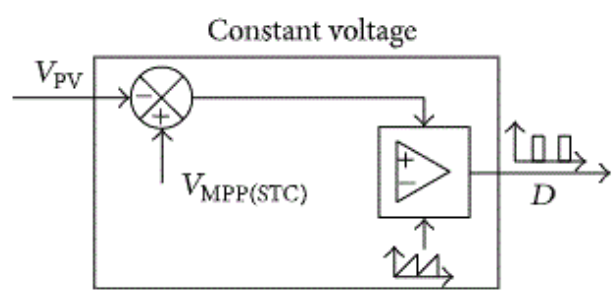

Figure 1. MPP voltage regulator using negative feedback

Many techniques are available in the literature, that propose different MPP methods, in considering effectiveness, range of accuracy, convergence speed, and reliability with the variation of environment conditions such as irradiation and/or temperature change [5]. These techniques differ in many aspects, such as maximum power tracking search algorithm, static or dynamic usage, online or offline connection, arithmetic models or artificial intelligence methods. For instance, online methods need continuous sampling of environment and system whereas offline techniques are simpler, and the operating points are predefined for specific conditions, without system data update [6].

Search techniques use disturbances in system variables, such as voltage, to find the maximum power point, which is used as the parameter to design the MPP [7]. Among the so many algorithms employed in MPPT problem, the P\&O (Perturb and Observe) [8] and the Incremental Conductance algorithms are the most common [9]. Their main advantages are the easy implementation, low computational demand, and only the measured voltage and current are required as information about the PV array. But they also have some drawbacks, like oscillations around the MPP in steady-state conditions and poor tracking under rapidly changing irradiation levels. This is due to the fact, that the search for maximum power point is related to the choice of the perturbation step. The latter infects the convergence time and the amplitude of the oscillations antagonistically.

Other MPPT algorithms are implemented with fuzzy logic 
and neural networks, or artificial intelligence (AI) algorithms, using logical and mathematical models [10], that might require high computational resources, to reach a reliable solution. To overcome these disadvantages and to make the response faster, an optimization technique influenced by the behavior of ant colonies is proposed [11, 12], which requires two control variables, such as input voltage and duty ratio of the converters.

To enhance the performance of the existing methods, several revolutionary computing algorithms are proposed, such as particle Swarm Optimization (PSO), Bacterial Foraging Algorithm (BFA), Ant Colony Optimization (ACO), and Genetic Algorithm (GA) [13, 14]. Other techniques are based on Sliding Mode Control (SMC) method [15] are used for robust performance to parameter variations, such as nonlinear synergetic controls. Other techniques require lookup tables and curve fitting.

A new and simple implemented optimization algorithm is the Owl Search Algorithm (OSA), which is combined with the $\mathrm{P} \& \mathrm{O}$ technique to track the MPP under steady and non-steady irradiation and temperature conditions [16].

In this paper, an accurate method is proposed to track the maximum power point of a photovoltaic module. The method is based on a mathematical model of the PV module to compute the theoretical value of the MPP voltage, for an online measured PV current, PV voltage, irradiance, and temperature. The method has the advantage of accuracy without any oscillations, as with some previously mentioned methods. This accuracy depends of course on the accuracy of the model. The MPPT algorithm has also the ability to track, with a fast speed, the maximum power point under variable atmospheric conditions and load changes. Simulation and experimental tests were performed to validate the method.

Whereas model free system uses measurements to obtain the maximum power point, model-based methods require system parameters, such as internal circuit resistance, current or voltage in the STC.

\section{PV MODEL}

The PV cell is simply represented as a current source Iph, related with irradiance, in parallel with a diode of fed current of ID related with generated voltage and temperature. It is appropriate to include a small series resistance RS and a larger parallel resistance RP, as shown in Figure 2.

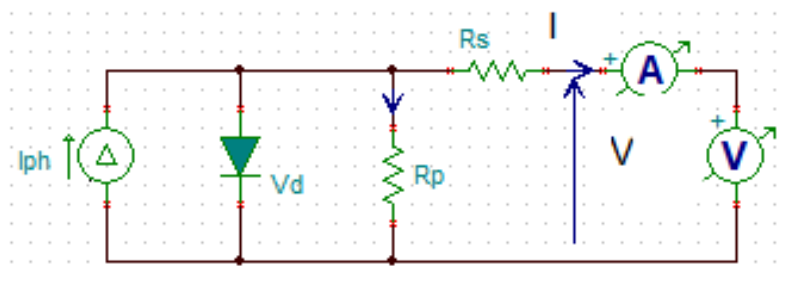

Figure 2. Typical equivalent circuit of a photovoltaic cell, with current-voltage measurements

An ammeter and a voltmeter are connected to measure the output current I and voltage $\mathrm{V}$, of the output load. These values can assist in the process of defining the maximum power point.

As PV cells are connected in series to increase terminal voltage, as well as in parallel to increase supplied current, the formulated equation of the output current is

$$
I=N_{P} I_{P V}-N_{P} I_{o}\left\{e^{\left[\frac{q\left(V+I R_{S}\right)}{N_{S} K A T_{o}}\right]}-1\right\}-\frac{N_{P}\left(V+I R_{S}\right)}{R_{P}}
$$

where, IPV

$$
I_{P V}=\left[I_{S C}+K_{i}\left(T_{o}-T_{r}\right)\right] S / S_{r}
$$

where, $\mathrm{N}_{S}$ and $\mathrm{N}_{\mathrm{P}}$ are the number of series and parallel connected cells respectively.

It can be noted that to find the I-V relationship, both temperature $\mathrm{T}$ and irradiance $\mathrm{S}$ are to be included. Consequently, it is required to measure all four parameters: I, $\mathrm{V}, \mathrm{T}$, and $\mathrm{S}$. The series resistance $\mathrm{R}_{\mathrm{S}}$ is normally very small, while the parallel resistance $\mathrm{R}_{\mathrm{P}}$ is large, hence it is possible to simplify the equivalent circuit by ignoring both of them.

Figure 3 demonstrates the effect of irradiance and operating cell temperature on the I-V relationship. In essence, current is linearly proportional with solar irradiance, and inversely proportional with temperature, while the effect is minor on the voltage. It can be noticed that the slopes of $\mathrm{dV} / \mathrm{dI}$ and $\mathrm{dI} / \mathrm{dV}$ are same for any irradiance or temperature.

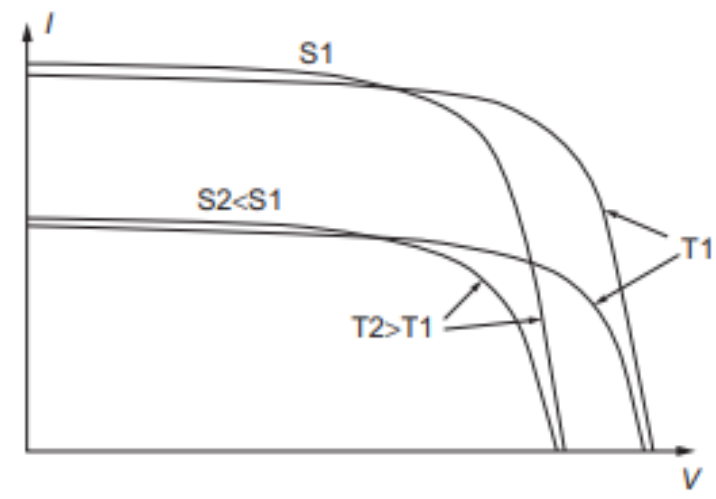

Figure 3. Irradiance and temperature effects on I-V relationship

\subsection{MIT model}

The equivalent circuit of a PV cell has been simulated in several expressions, depending on complexity, accuracy and variables used. To find an expression under nonreferenced irradiance and operational temperature, the MIT model is employed, also named the Jet Propulsion Lab (JPL). It is a useful model for our proposed relaxation method in determining the MPP. In this model, the I-V depends only on $\mathrm{I}_{\mathrm{SC}}, \mathrm{I}_{\mathrm{MP}}, \mathrm{V}_{\mathrm{MP}}$ and $\mathrm{V}_{\mathrm{OC}}$, as

$$
I=I_{S C}-I_{S C} C_{1} \exp \left(\frac{V}{C_{2} V_{O C}}-1\right)
$$

where,

$$
\begin{gathered}
C_{1}=\left(1-\frac{I_{M P}}{I_{S C}}\right) \exp \left(\frac{V_{M P}}{C_{2} V_{O C}}\right) \\
C_{2}=\left(\frac{V_{M P}}{V_{O C}}-1\right) / \ln \left(1-\frac{I_{M P}}{I_{S C}}\right)
\end{gathered}
$$

In fact, $\mathrm{I}_{\mathrm{MP}}, \mathrm{V}_{\mathrm{MP}}$ can be determined from $\mathrm{I}_{\mathrm{SC}}$ and $\mathrm{V}_{\mathrm{OC}}$ too. 
Figure 3 depicts the I-V relation for general non referenced conditions.

The characteristic can be extended to referenced conditions of irradiance and temperature, as well as the shunt and series resistances representing the detailed equivalent circuit of a PV cell. In general, current is proportional to irradiance, whereas voltage is related to temperature, hence both of them can be related to the referenced values as

$$
I_{S C}=I_{S C R} S
$$

and

$$
V_{O C}=V_{O C R}-0.0023 T_{A}(T-25)
$$

where, $I_{S C R}$ is the referenced short circuit at $1 \mathrm{~kW} / \mathrm{m}^{2}, \mathrm{~S}$ is operational irradiance in $\mathrm{kW} / \mathrm{m}^{2}, \mathrm{~V}_{\mathrm{OCR}}$ is referenced open circuit voltage at $25^{\circ} \mathrm{C}, \mathrm{T}_{\mathrm{A}}$ is the ambient temperature and $\mathrm{T}$ is the solar cell temperature, which is defines as

$$
T=T_{A}+\frac{(N O C T-20) S}{0.8}
$$

NOCT is the normal operating cell temperature of the PV cell when operating under the conditions of $\mathrm{S}=0.8 \mathrm{~kW} / \mathrm{m}^{2}$, and ambient temperature of $20^{\circ} \mathrm{C}$. Thereafter the maximum power can be calculated as

$$
P_{M P}=I_{S C} V_{O C} F F
$$

where, $\mathrm{FF}$ is the fill factor defined as $\mathrm{P}_{\mathrm{MPR}} /\left(\mathrm{I}_{\mathrm{SCR}} \mathrm{V}_{\mathrm{OCR}}\right)$, with $\mathrm{P}_{\mathrm{MPR}}$ is the referenced maximum power, declared by the manufacturer.

\subsection{Irradiance and temperature dependency}

The most basic and important electrical characteristics of PV cells are the open-circuit voltage, short circuit current and maximum power point, which are affected by both irradiance and operational temperature. The temperature coefficient for the open-circuit voltage of a PV cell is around $-2.2 \mathrm{mV} /{ }^{\circ} \mathrm{C}$, and can be accumulated with the use of more cells connected in series, whereas the current coefficient is about $5 \mathrm{uA} /{ }^{\circ} \mathrm{C}, / \mathrm{cm}^{2}$, which can be neglected. On the other hand, short-circuit current is proportional to the daily irradiance, and can be related to $1 \mathrm{~kW} / \mathrm{m}^{2}$ reference. Since the voltage is a logarithmic function of current, it will also vary logarithmically with irradiance.

Figure 4 depicts the voltage and current dependencies on irradiance at a reference operating temperature of $25^{\circ} \mathrm{C}$, whereas Figure 5 depicts the variations of voltage and current with temperature at a constant solar irradiance of $1000 \mathrm{~W} / \mathrm{Sq}$. $\mathrm{m}$. These figures are based on the MIT model that used as a reference platform for other environmental conditions of irradiance and temperature.

The difference between cell temperature and ambient temperature is linearly dependent on irradiance as well, with factor $[N O C T-20] S / 0.8$, where NOCT stands for Normal Operating Cell temperature, and $\mathrm{S}$ is irradiance in $\mathrm{kW} / \mathrm{m}^{2}$. In order to simplify all variations, it is customary to neglect both voltage variation due to irradiance and current variation due to operational temperature.

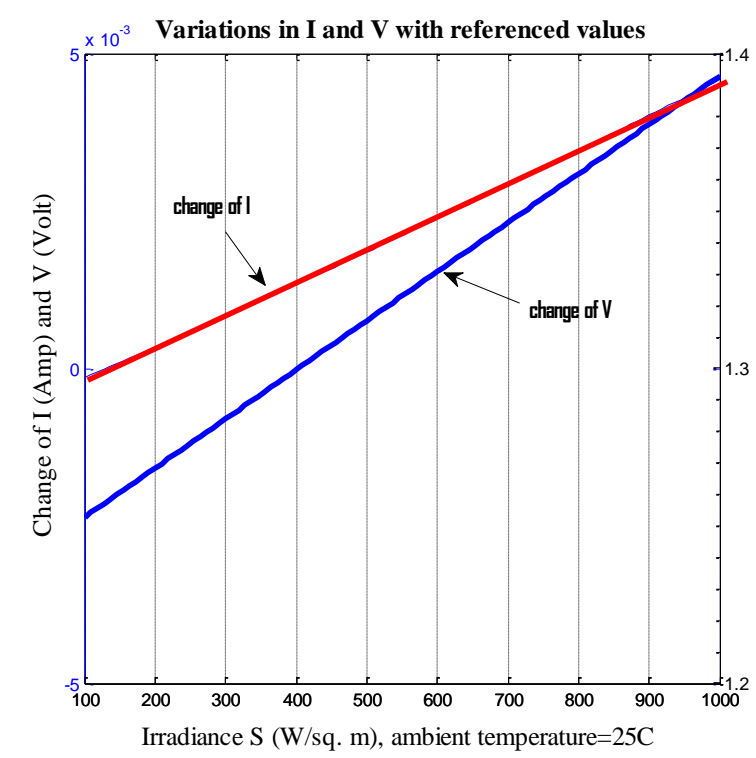

Figure 4. Variations of I-V with irradiance at constant temperature

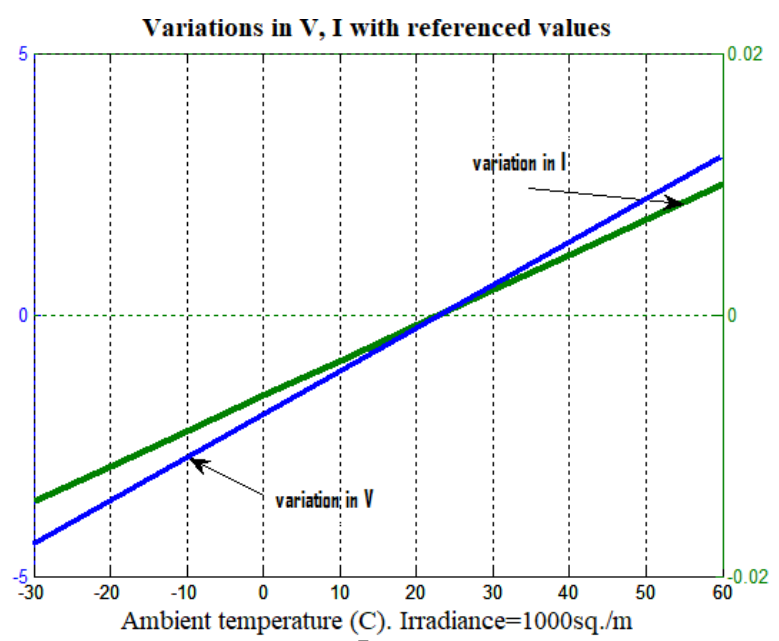

Figure 5. I-V variations with temperature at constant irradiance

\section{MPPT METHODS}

The output dc power of a PV cell or module is $\mathrm{V} x \mathrm{I}$, which is variable with both of them, reaching a maximum of PMP, and in order to extract maximum power, we need to operate dynamically on load at the maximum power point MPP. That is when $\mathrm{dP} / \mathrm{dV}=0$. It is noted that this point depends on continuous variations of the output load, as well as with irradiation and operational temperature. This is mostly required especially for PV modules power in excess of $1 \mathrm{~kW}$.

For lower output powers, a simpler yet efficient algorithm is needed to trace MPP.

\subsection{Relaxation method}

The I-V characteristic of a PV cell has the same pattern for any variations in environmental irradiation or operational temperature. The current varies almost linearly with small slope before the maximum power point MPP, and also in a 
linear matter with large slope after the MPP point. In almost all cases, the MPP lies between these two regions.

Figure 6 demonstrates a general I-V pattern of a PV cell with two slope lines, that's $\Delta \mathrm{I} / \Delta \mathrm{V}$, at the short circuit current $\mathrm{I}_{\mathrm{SC}}$ and open circuit voltage $\mathrm{V}_{\mathrm{OC}}$, in which the former represents the series resistance $\mathrm{R}_{\mathrm{S}}$, while the latter represents the shunt resistance $\mathrm{R}_{\mathrm{SH}}$,

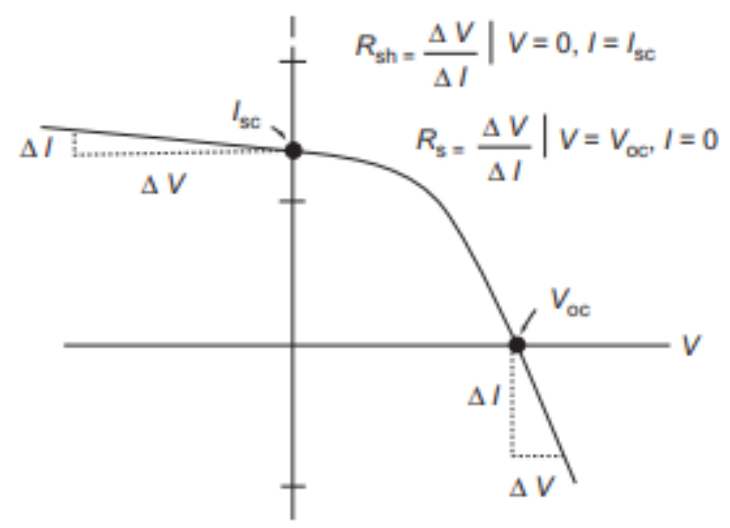

Figure 6. Effects of $R_{S}$ and $R_{P}$ on $I-V$ curve pattern

The maximum power point is normally determined from the power-voltage characteristic as depicted in Figure 7. As seen, the three shown slopes represent the conductance $G=I / V$, at different curve locations with maximum power point located at $\mathrm{G}=0$. It can be noted that MPP voltage can also be approximated from the intersection of $\mathrm{G}>0$ and $\mathrm{G}<0$, yet this has not been investigated in this study.

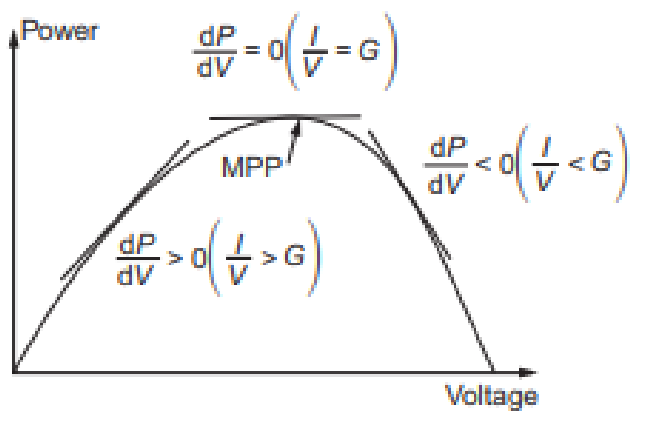

Figure 7. Power-voltage relationship

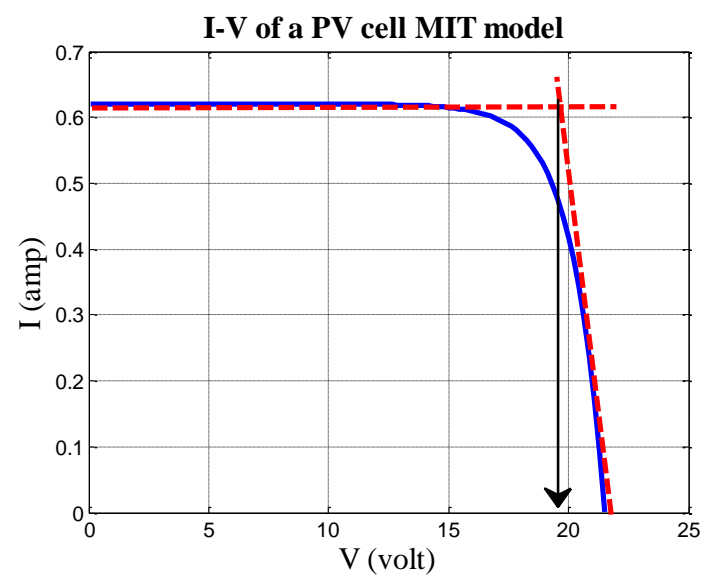

Figure 8. Slope method in the I-V relationship
The slope method of determining MPP voltage, is used in the I-V relationship, as shown in Figure 8 to give reasonably accurate value for small and medium module ratings within $1 \mathrm{~kW}$. It can be seen that using MIT model, the MPP voltage of $19.9 \mathrm{~V}$ is determined, compared with $19.6 \mathrm{~V}$ as reported by module data.

It can also be seen that this same MPP voltage can be determined with the $\mathrm{P}-\mathrm{V}$ relationship with a similar accuracy, as depicted in Figure 9.

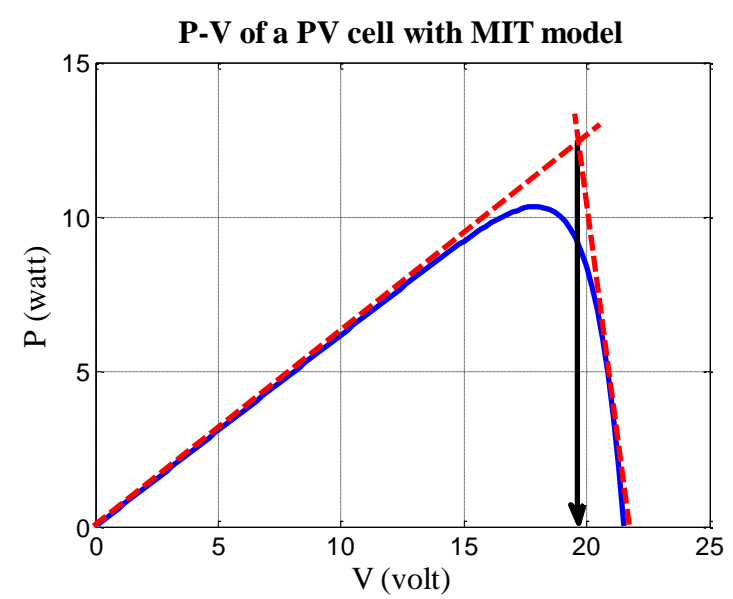

Figure 9. Slope method in the P-V relationship

We shall implement the method on the I-V relationship, since they are readily available for the implemented mathematical model. It must be emphasized that these relationships depend on irradiance and operating voltage, and the method can only be applied when these environmental effects are taken into consideration.

\subsection{Load resistance effect}

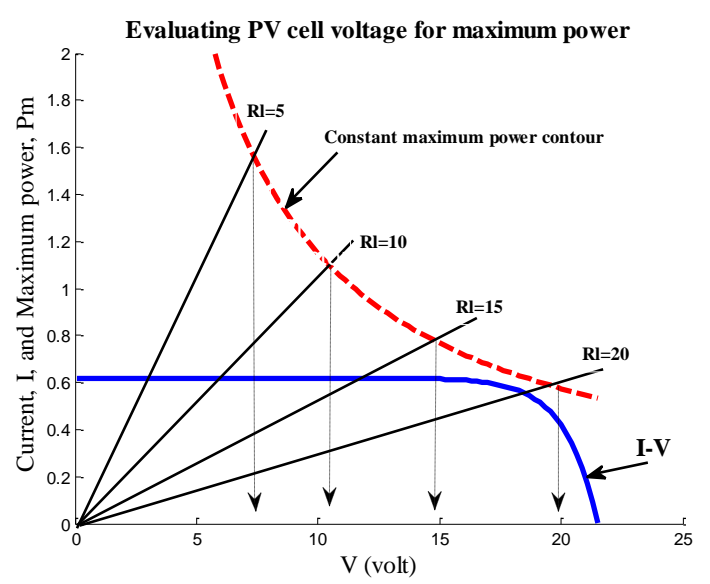

Figure 10. Estimating MPP voltage for different load resistances

The load resistance determines the MPP for fixed values of irradiance and operating temperature. Figure 10 demonstrates different values of load resistances ranging from 5-20 $\Omega$, that are drawn in the I-V for the PV module studied in this work. The maximum power point power is calculated as a constant value of $\operatorname{Imp} \times \mathrm{Vmp}$ and drawn for different values of voltages and currents as shown. The load resistance lines are intersecting this constant maximum power curve at different values of voltages, with smaller voltages at lower resistances. 
These voltages represent the controlled output voltages needed to operate at MPP region, as feedback values to be compared with PV measured voltages used as references for the feedback, as shown in Figure 1. Here, the curve scale of constant maximum power is only representative, yet it will be evaluated in simulating a case study.

Analytically, it can be deduced that the equations of the two slopes lines of the I-V relationship at Voc and Isc are

$$
\begin{gathered}
V_{m}=\left(I_{s c} R_{s}-V_{o c}\right) /\left(\frac{R_{s}}{R_{p}}-1\right) \\
I_{m}=I_{s c}-V_{m} / R_{p}
\end{gathered}
$$

and the intersection of these two lines is the MPP voltage, with maximum power evaluated as $V_{m} \times I_{m}$, hence the MPP output controlled voltage can be determined at any load resistance as the projection at the constant power curve intersections, as demonstrated in Figure 10, that's

$$
V_{o}=\sqrt{V_{m} I_{m} R_{L}}
$$

It can be noted that the controlled output voltages $V_{o}$ is smaller at lower values of load resistances, than at larger load resistances. A Buck-Boost converter is normally used to bring the measured PV cell voltage $\mathrm{V}_{\mathrm{PC}}$ to the MPP controlled voltage $\mathrm{V}_{\mathrm{o}}$ with controlled duty cycle (D) evaluated

$$
D=\left(V_{o}-V_{P C}\right) / V_{o}
$$

In this method, tracking MPP with voltage perturbations, is carried out once without the continuous variations of voltage and power monitoring as for example in the P\&O method, and other methods, with eliminated oscillations of tracking.

\section{SIMULATION AND CASE STUDIES}

\subsection{MIT model simulation}

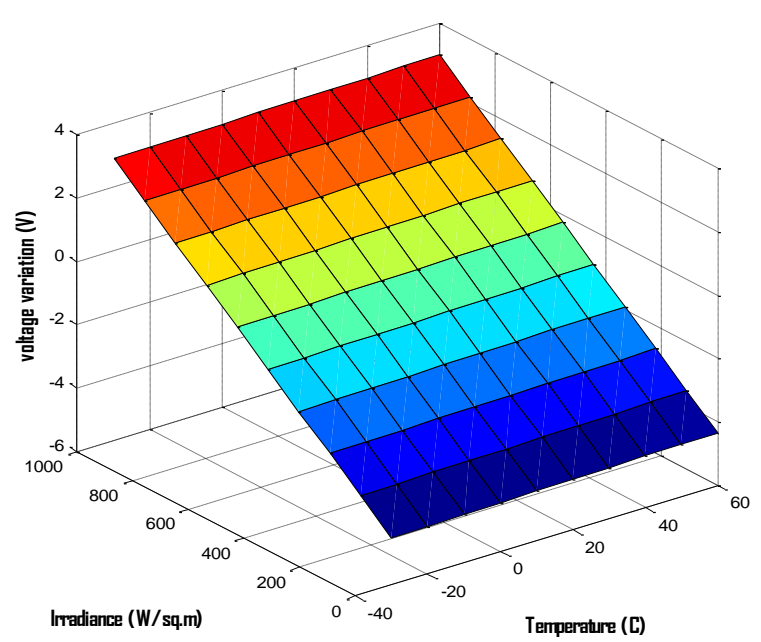

Figure 11. Variation of voltage with irradiance and temperature

The accuracy of the MIT model of simulating the PV cell requires evaluation of voltage and current variation with the two main effects, that are temperature and irradiance. Figure 11 depicts the variation of PV cell voltage with respect to both temperature and irradiance.

It can be noted that the effect of temperature in minimum, whereas voltage is linearly proportional with irradiance.

Similarly, Figure 12 shows a surface of current variation with temperature and irradiance.

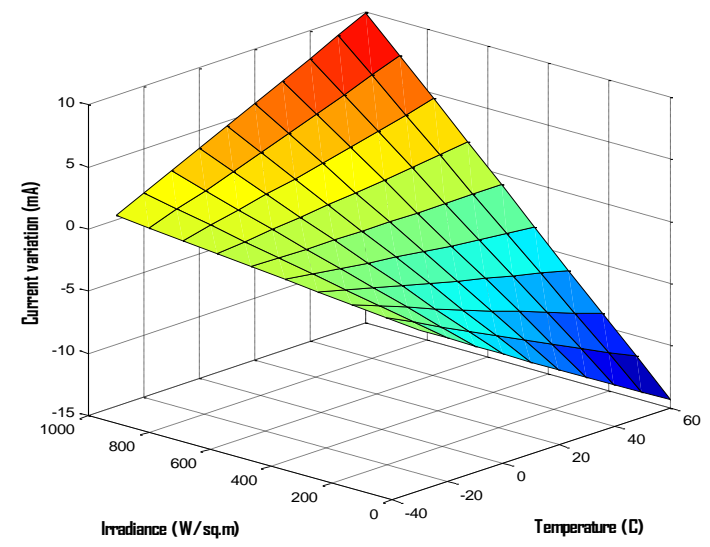

Figure 12. Variation of current with irradiance and temperature

Apart from temperature and irradiance effects on working at maximum power point, the variation of the load resistance changes MPP location. Figure 13 demonstrates the effect of load resistance changes on controlling the output voltage on the output load, which can be a battery for the case of standalone setup or connected with the ac grid network.

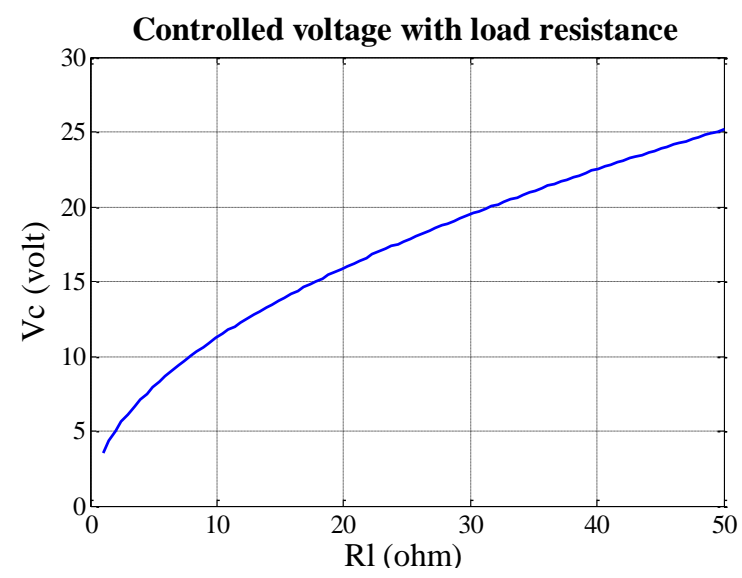

Figure 13. Output controlled voltage with different load resistances

\subsection{MPP controlled voltage simulations}

The case studies simulations are based on the data of a PV module that was used for its equivalent circuit represented in the MIT model, as indicated in Table 1 . The method of finding MPP is demonstrated with variations of temperature in the range of $10^{\circ} \mathrm{C}-40^{\circ} \mathrm{C}$, with variations in irradiance in the range of $200 \mathrm{~W} / \mathrm{m} 2-1000 \mathrm{~W} / \mathrm{m} 2$, as well as 3 variations in load resistance of 10,30 and $50 \Omega$. The $30 \Omega$ resistance represents approximately the characteristic resistance of the PV cell, as per following studied module data, since it is equal to $V m p / I m p=16.9 / 0.6=28.167 \Omega$. 
Table 1. PV module data used in study

\begin{tabular}{c|c|c}
\hline Name & Symbol & value \\
\hline Module power & Pmp & $10 \mathrm{~W}$ \\
MMP voltage & Vmp & $16.9 \mathrm{~V}$ \\
MMP current & Imp & $0.6 \mathrm{~A}$ \\
Open circuit voltage & Voc & $21.5 \mathrm{~V}$ \\
Short circuit current & Isc & $0.62 \mathrm{~A}$ \\
Series resistance & $\mathbf{R s}$ & $1.72 \Omega$ \\
Parallel resistance & $\mathbf{R p}$ & $28 \mathrm{~K} \Omega$ \\
Current coefficient & $\boldsymbol{\alpha}$ & $0.27 \mathrm{~mA} /{ }^{\circ} \mathrm{C}$ \\
Voltage coefficient & $\boldsymbol{\beta}$ & $-82.4 \mathrm{mV} /{ }^{\circ} \mathrm{C}$ \\
\hline
\end{tabular}

Under these different values of irradiance and operating temperature, the MPP controlled voltage is evaluated for different values of load resistances, as depicted in Table 2.

Table 2. MPP controlled voltage for variations in irradiance, temperature and load resistance

\begin{tabular}{c|c|c|c|c}
\hline Temperature & Irradiance & \multicolumn{3}{|c}{$\mathbf{( M P P )}$ controlled voltage Vo } \\
& $\mathbf{S , ~ W / \mathbf { m } ^ { 2 }}$ & $\mathbf{R}=\mathbf{1 0}$ & $\mathbf{R I}=\mathbf{3 0}$ & $\mathbf{R I}=\mathbf{5 0}$ \\
& & $\boldsymbol{\Omega}$ & $\boldsymbol{\Omega}$ & $\boldsymbol{\Omega}$ \\
\hline $25{ }^{\circ} \mathrm{C}$ & 200 & 11.3375 & 19.6367 & 25.3509 \\
$25^{\circ} \mathrm{C}$ & 500 & 11.4823 & 19.8879 & 25.6752 \\
$25{ }^{\circ} \mathrm{C}$ & 1000 & 11.7395 & 20.3335 & 26.2504 \\
$10{ }^{\circ} \mathrm{C}$ & 200 & 10.9886 & 19.0329 & 24.5713 \\
$10{ }^{\circ} \mathrm{C}$ & 500 & 11.1275 & 19.2735 & 24.8819 \\
$10{ }^{\circ} \mathrm{C}$ & 1000 & 11.3731 & 19.6988 & 25.4311 \\
$40{ }^{\circ} \mathrm{C}$ & 200 & 11.6763 & 20.2239 & 26.1090 \\
$40{ }^{\circ} \mathrm{C}$ & 500 & 11.8284 & 20.4875 & 26.4492 \\
$40{ }^{\circ} \mathrm{C}$ & 1000 & 12.0989 & 20.9559 & 27.0540 \\
\hline
\end{tabular}

In order to verify the proposed MIT method in evaluating maximum power point, a load resistance of $30 \Omega$ is selected to be similar to the characteristic resistance of the adopted PV module in this study. Table 3 depicts the determined controlled voltage $\mathrm{V}_{0}$ to evaluate maximum power point voltage ( $\mathrm{Vmp}$ ), with a controlled converter duty cycle (D). Maximum current and power are also evaluated at the MPP.

Table 3. Duty cycle values used to control output voltage for MPP volatge

\begin{tabular}{cccccc}
\hline $\begin{array}{c}\mathbf{S} \\
\mathbf{W} / \mathbf{m}^{\mathbf{2}}\end{array}$ & $\mathbf{V o}$ & $\mathbf{C}$ MIT Model & Imp & Pmp & Duty cycle \\
$\mathbf{D} \%$ \\
\hline 200 & 19.6367 & 20.4366 & 0.6188 & 12.6456 & -4.0735 \\
500 & 19.8879 & 20.4360 & 0.6190 & 12.6491 & -2.7559 \\
1000 & 20.3335 & 20.4350 & 0.6193 & 12.6548 & -0.4992 \\
200 & 19.0329 & 19.2033 & 0.6180 & 11.8678 & -0.8953 \\
500 & 19.2735 & 19.2069 & 0.6170 & 11.8503 & 0.3456 \\
1000 & 19.6988 & 19.2129 & 0.6153 & 11.8210 & 2.4666 \\
200 & 20.2239 & 21.6699 & 0.6195 & 13.4254 & -7.1500 \\
500 & 20.4875 & 21.6651 & 0.6209 & 13.4528 & -5.7479 \\
1000 & 20.9559 & 21.6572 & 0.6233 & 13.4984 & -3.3466 \\
\hline
\end{tabular}

Note: A load resistance of $30 \Omega$ is used. The first blue highlighted 3 values are for temperature of $25^{\circ} \mathrm{C}$, the second green highlighted 3 values are for $10^{\circ} \mathrm{C}$, and the third orange 3 values are for $40^{\circ} \mathrm{C}$.

\subsection{Case study}

The evaluation of MMP controlled voltage is demonstrated in a general case study according to variations of irradiance $(\mathrm{S})$ and operating temperature $(T)$ as well as load resistance $\left(R_{L}\right)$, as depicted in Figure 14, in which three time incidents during daily sun path, are selected to implement the employed method in selecting MPP voltages.

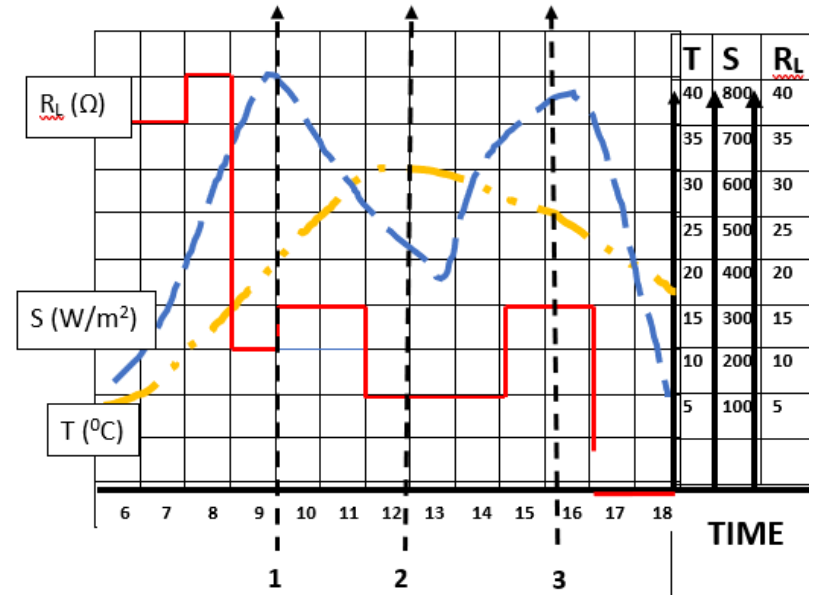

Figure 14. MPP method case study

The MPP controlled voltage as well as voltage and current perturbations are tabulated in Table 4, for different values of irradiance $(\mathrm{S})$, temperature $(\mathrm{T})$ and load resistances $(\mathrm{R})$, at different instants of time. It must be noted that variations of load resistance is normally at higher pace than both irradiance and temperature variations during the sun path 6 AM- 6 PM. These parameters are selected to correspond with the data of the PV module that is implemented in this study.

Table 4. MPP voltage with current and voltage vairations at three different time incidents

\begin{tabular}{c|c|c|c|c|c|c}
\hline & $\begin{array}{c}\mathbf{S} \\
\mathbf{W} / \mathbf{m}^{\mathbf{2}}\end{array}$ & $\begin{array}{c}\mathbf{T} \\
{ }^{\mathbf{0}}\end{array}$ & $\begin{array}{c}\mathbf{R} \\
\mathbf{\Omega}\end{array}$ & $\begin{array}{c}\text { MPP } \\
\text { Voltage }\end{array}$ & $\mathbf{d V}$ & $\mathbf{d I}$ \\
\hline Time 1 & 800 & 20 & 10 & 20.4354 & 0.3445 & -0.1237 \\
Time 2 & 400 & 30 & 5 & 20.4362 & 0.7056 & -0.3719 \\
Time 3 & 700 & 25 & 15 & 20.4356 & 0.4348 & -0.1857 \\
\hline
\end{tabular}

\section{CONCLUSIONS}

A relaxation algorithm is proposed for small and medium sized PV modules, in which the I-V pattern at reference values, is reduced to two linear slopes, intersecting at the maximum power point. The slopes depend on the series and parallel resistances of the equivalent PV cell circuit. The controlled voltage to be used in the Buck-Boost converter, depends on the evaluated maximum power and load resistance.

The well-known MIT or JPL non-referenced method of analyzing the equivalent circuit is implemented, that doesn't depend on continuous measurements of irradiance and operating temperature. The entire analysis is mathematical and requires one V-I measurements per load resistance value, and as irradiance and temperature vary, the MIT model is adjusted according to mathematical formulations.

A simulation case study is used to evaluate the duty cycle of a voltage converter, and to compare the used MIT method with the data of an implemented PV module.

\section{REFERENCES}

[1] Hodge, B.K. (2010). Photovoltaic systems. Alternative Energy Systems and Applications, A book published by John Wiley \& Sons, 225-248. ISBN:978-0-470-14250-9

[2] Freris, L. Infield, D. (2008). Electrical power generation and conditioning. Renewable Energy in Power Systems, 
book published by WILEY, 97-147. ISBN: 978-0-47001749-4

[3] Markvart, T. (2000). Photovoltaic system engineering. Solar Electricity. John Wiley \& Sons, 82-136. ISBN:0471-98853-7.

[4] Bhatnagar, P., Nema, R.K. (2013). Maximum power point tracking control techniques: State-of-the-art in photovoltaic applications. Renewable and Sustainable Energy Reviews, 23: 224-241. https://doi.org/10.1016/j.rser.2013.02.011.

[5] Villalva, M.G., Gazoli, J.R., Ruppert Filho, E. (2009). Comprehensive approach to modeling and simulation of photovoltaic arrays. IEEE Transactions on Power Electronics, 24(5): 1198-1208. https://doi.org/10.1109/TPEL.2009.2013862

[6] Hohm, D.P., Ropp, M.E. (2003). Comparative study of maximum power point tracking algorithms. Progress in Photovoltaics: Research and Applications, 11(1): 47-62. https://doi.org/10.1002/pip.459

[7] El Fadili, A., Giri, F., El Magri, A. (2013). Reference voltage optimizer for maximum power tracking in singlephase grid-connected photovoltaic systems. Journal of Control and Systems Engineering, 1(2): 57.

[8] Petrone, G., Spagnuolo, G., Teodorescu, R., Veerachary, M., Vitelli, M. (2008). Reliability issues in photovoltaic power processing systems. IEEE transactions on Industrial Electronics, 55(7): 2569-2580. https://doi.org/10.1109/TIE.2008.924016

[9] Qin, S., Wang, M., Chen, T., Yao, X. (2011). Comparative analysis of incremental conductance and perturb-and-observation methods to implement MPPT in photovoltaic system. In 2011 International Conference on Electrical and Control Engineering, 5792-5795. https://doi.org/10.1109/ICECENG.2011.6057704

[10] El Jouni, A., El Bachtiri, R. (2008). A maximum power point tracking fuzzy logic controller for photovoltaic pumping system. International Scientific Journal for Alternative Energy and Ecology, 5(61): 51-57.

[11] El Jouni, A., El-Bachtiri, R., Boumhidi, J. (2006). Sliding mode controller for the maximum power point tracking of a photovoltaic pumping system. WSEAS Transactions on Power Systems, 1(10): 1675.

[12] Dorigo, M., Gambardella, L.M. (1997). Ant colony System: Optimization by a colony of cooperating agents. IEEE Transactions on Systems, Man and Cybernetics, (Part B), 29-41.

[13] Miyatake, M., Veerachary, M., Toriumi, F., Fujii, N., Ko, H. (2011). Maximum power point tracking of multiple photovoltaic arrays: A PSO approach. IEEE Transactions

on Aerospace and Electronic Systems, 47(1): 367-380. https://doi.org/10.1109/TAES.2011.5705681

[14] Borni, A., Abdelkrim, T., Bouarroudj, N., Bouchakour, A., Zaghba, L., Lakhdari, A., Zarour, L. (2017). Optimized MPPT controllers using GA for grid connected photovoltaic systems, comparative study. Energy $\quad$ Procedia, 119: 278-296. https://doi.org/10.1016/j.egypro.2017.07.084

[15] Mehiri, A., Bettayeb, M., Hamid, A.K. (2019). Fractional nonlinear synergetic control based MPPT Algorithm for PV System. In 2019 Advances in Science and Engineering Technology International Conferences (ASET), $\mathrm{pp}$ https://doi.org/10.1109/ICASET.2019.8714527

[16] Jain, M., Maurya, S., Rani, A., Singh, V. (2018). Owl search algorithm: A novel nature-inspired heuristic paradigm for global optimization. Journal of Intelligent \& Fuzzy Systems, 34(3): 1573-1582. https://doi.org/10.3233/JIFS-169452

\section{NOMENCLATURE}

$\mathrm{N}_{\mathrm{P}}$

$\mathrm{I}_{\mathrm{PV}}$

$\mathrm{I}_{\mathrm{o}}$

$\mathrm{q}$

$\mathrm{V}$

I

$\mathrm{R}_{\mathrm{S}}$

$\mathrm{N}_{S}$

$\mathrm{K}$

A

$\mathrm{T}_{\mathrm{o}}$

$\mathrm{R}_{\mathrm{P}}$

$\mathrm{I}_{\mathrm{SC}}$

$\mathrm{K}_{\mathrm{i}}$

$\mathrm{T}_{\mathrm{r}}$

$\mathrm{S}$

$\mathrm{S}_{\mathrm{r}}$

$\mathrm{C}_{1}, \mathrm{C}_{2}$

$\mathrm{V}_{\mathrm{OC}}$

$\mathrm{V}_{\mathrm{MP}}$

$\mathrm{I}_{\mathrm{MP}}$

$\mathrm{I}_{\mathrm{SCR}}$

$\mathrm{V}_{\mathrm{OCR}}$

$\mathrm{T}_{\mathrm{A}}$ NOCT number of parallel cells in module

PV cell current, A

diode reverse (dark) current, $\mathrm{A}$

electron charge, columb

Measured cell output voltage

Measured cell output current

Series resistance

Number of series cells in module

Boltzmann constant

Efficiency constant

Cell operating temperature

Parallel resistance

Short circuit current

Constant

Reference temperature

Irradiance

Reference irradiance

Symbols used in MIT equations

Open circuit voltage

Maximum power point voltage

Maximum power point current

Short circuit current for a referenced value

Open circuit voltage for a referenced value

Ambient temperature

Normal Operating Cell Temperature 